\title{
Bioavailability of tocotrienols: evidence in human studies
}

\author{
Ju-Yen Fu ${ }^{1,4^{*}}$, Hui-Ling Che ${ }^{1,2}$, Doryn Meam-Yee Tan ${ }^{1,3}$ and Kim-Tiu Teng ${ }^{1}$
}

\begin{abstract}
As a minor component of vitamin E, tocotrienols were evident in exhibiting biological activities such as neuroprotection, radio-protection, anti-cancer, anti-inflammatory and lipid lowering properties which are not shared by tocopherols. However, available data on the therapeutic window of tocotrienols remains controversial. It is important to understand the absorption and bioavailability mechanisms before conducting in-depth investigations into the therapeutic efficacy of tocotrienols in humans. In this review, we updated current evidence on the bioavailability of tocotrienols from human studies. Available data from five studies suggested that tocotrienols may reach its target destination through an alternative pathway despite its low affinity for a-tocopherol transfer protein. This was evident when studies reported considerable amount of tocotrienols detected in HDL particles and adipose tissues after oral consumption. Besides, plasma concentrations of tocotrienols were shown to be higher when administered with food while self-emulsifying preparation of tocotrienols was shown to enhance the absorption of tocotrienols. Nevertheless, mixed results were observed based on the outcome from 24 clinical studies, focusing on the dosages, study populations and formulations used. This may be due to the variation of compositions and dosages of tocotrienols used, suggesting a need to understand the formulation of tocotrienols in the study design. Essentially, implementation of a control diet such as AHA Step 1 diet may influence the study outcomes, especially in hypercholesterolemic subjects when lipid profile might be modified due to synergistic interaction between tocotrienols and control diet. We also found that the bioavailability of tocotrienols were inconsistent in different target populations, from healthy subjects to smokers and diseased patients. In this review, the effect of dosage, composition and formulation of tocotrienols as well as study populations on the bioavailability of tocotrienols will be discussed.
\end{abstract}

Keywords: Tocotrienols, Bioavailability, Human, Metabolism, Absorption, Vitamin E, Palm oil

\section{Introduction}

The biological role of tocotrienols, as minor components in vitamin $\mathrm{E}$, has been largely underestimated despite studies showing their unique physiological functions. In fact, tocotrienols possess similar structures to tocopherols characterized by a chromanol head named by $\alpha, \beta, \gamma$ or $\delta$ according to the position and degree of methylation $[1,2]$. Tocotrienols are differentiated from tocopherols by the degree of saturation at the side chains having 3 double bonds at carbons 3, 7 and 11 whereas tocopherols possess saturated phytyl side chains (Figure 1). Collective studies

\footnotetext{
* Correspondence: fujuyen@gmail.com

'Malaysian Palm Oil Board, 6 Persiaran Institusi, Bandar Baru Bangi, 43000 Kajang, Selangor, Malaysia

${ }^{4}$ Nutrition Unit, Division of Product Development and Advisory Services, Malaysian Palm Oil Board, 6 Persiaran Institusi, Bandar Baru Bangi, 43000 Kajang, Selangor, Malaysia

Full list of author information is available at the end of the article
}

found that tocotrienols exhibit interesting biological activities not shared by tocopherols, including neuroprotective, radio-protective, anti-cancer, anti-inflammatory and lipid lowering properties [2-8]. Nevertheless, scientific recognition for tocotrienols remains limited compared to tocopherols, being a form of vitamin $\mathrm{E}$ widely accepted by the public. One of the reasons is the low abundance of tocotrienols in food sources. In fact, many are not aware that up to $70 \%$ of vitamin $E$ from crude palm oil consists of tocotrienols whereas annatto contains the richest source of $\delta$-tocotrienol [9-11]. Red palm olein on the other hand contains up to $541 \mathrm{ppm}$ of tocotrienols together with a bouquet of palm phytonutrients [12]. Another reason that hurdles the advancement of tocotrienols is the lack of understanding on the bioavailability and behavior of tocotrienols in the human system. Although vitamin $\mathrm{E}$ in general has been well studied for their absorption and metabolic

\section{Biomed Central}




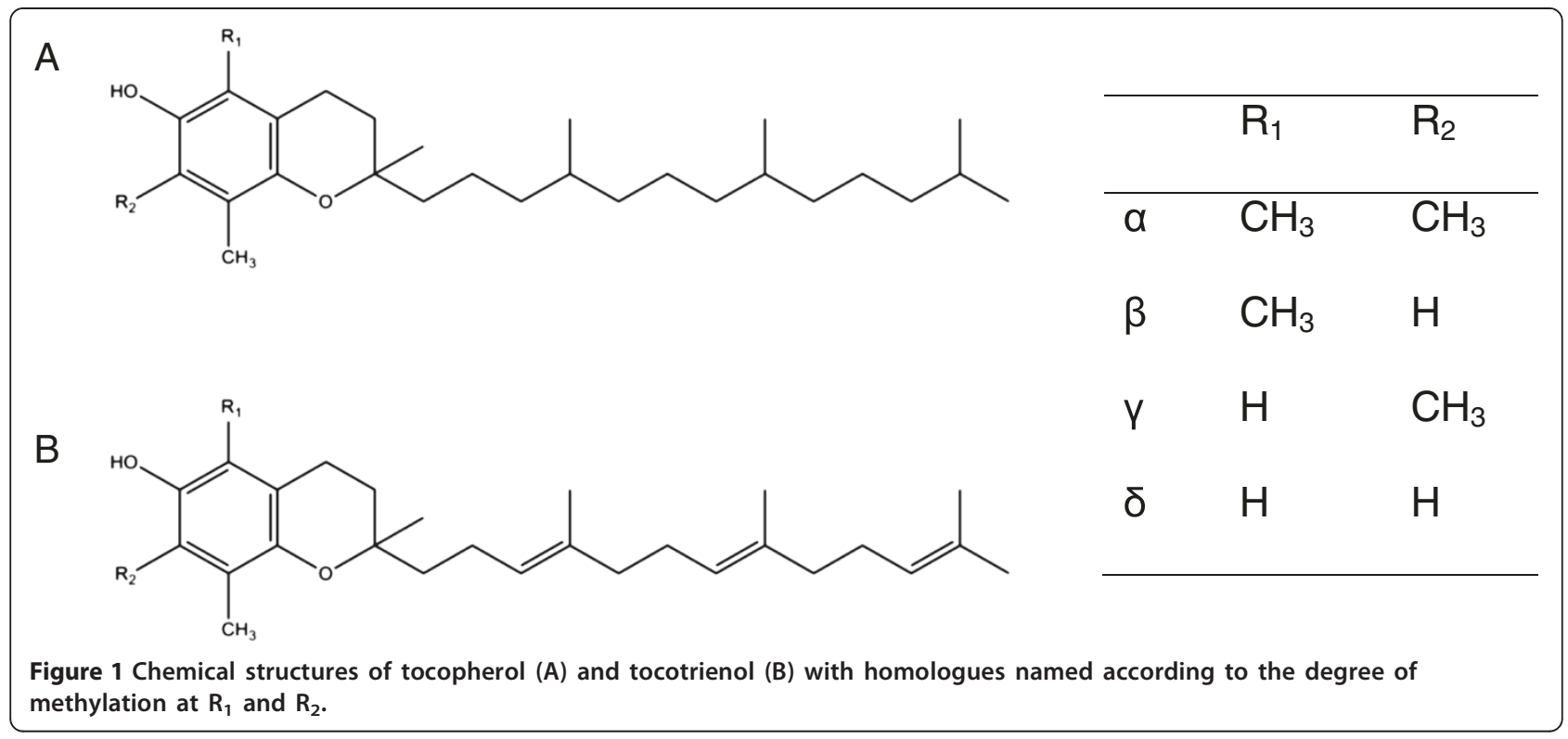

fate, the plasma concentrations of tocotrienols were found to be much lower compared to tocopherols. When the route of administration was investigated, the absorption of tocotrienols was negligible when administered via the intraperitoneal and intramuscular route, while incomplete absorption was observed when given via the oral route in rats [13]. Being a lipophilic compound, the absorption of vitamin $\mathrm{E}$ is essentially dependent on the degree of lipolysis and food intake when administered orally. Since then, several studies have undertaken the initiative to formulate tocotrienols in water soluble delivery systems to increase their solubility. The use of hydrophilic polymers such as cyclodextrin and emulsifiers including Tween 80 showed improved absorption and higher plasma concentrations when administered to rats $[14,15]$. Intravenous administration via tail vein injections was made possible for tocotrienols by formulating into suitable nano-carriers [16]. When encapsulated in a tumour-targeted vesicle system, tocotrienols are highly promising as a potential therapeutic system to eradicate human epithelial tumours and melanoma tumours in murine xenografts [17].

Although most studies were conducted in rodents and animals, they serve as a basis for clinical evaluations to establish their health benefits in humans. Several reviews have clearly summarized the unique properties of tocotrienols including their antioxidant, anticancer, cardioprotective and neuroprotective effects to name a few $[8,18]$. In addition, reviews by Kannappan et al. and Nesaretnem et al. provided extensive insights into the molecular targets of tocotrienols, especially in cancer and inflammation $[2,3,19]$. Over the past decade, a fair number of human studies for tocotrienols had emerged. Nevertheless, questions on the bioavailability of tocotrienols are complicated by many factors and remained unanswered. Therefore, it is now timely for us to re-examine these human studies in relative to the bioavailability and therapeutic window of tocotrienols in order to strategize the studies forward.

\section{Postprandial absorption and pharmacokinetics of tocotrienols}

Evidence on the metabolism of tocotrienols is relatively limited when compared with $\alpha$-tocopherol [20]. Only a handful of papers studied the postprandial distribution of tocotrienols thus far, using single dose tocotrienol-rich fractions (TRF) derived from palm oil [21-23]. Fairus et al. [21] reported that tocotrienols were transported in triacylglycerol (TAG)-rich fractions containing chylomicrons and VLDL, LDL and HDL cholesterols after administration of TRF at $1011 \mathrm{mg}$ in healthy subjects. In this study, $\alpha$-, $\gamma$ - and $\delta$-tocotrienols were detected in both plasma and lipoproteins in appreciable amount though $\alpha$-tocotrienol emerged as the major homologue detected. Unlike tocopherols which were distributed equally in all the lipoprotein fractions, tocotrienols were mainly detected in the HDL cholesterol at 4 to 8 hours before clearance. This observation suggests that tocotrienols may go through alternative metabolism pathway which warrants further investigation. Alpha-tocotrienol was suggested to be secreted by small HDL particles whilst $\alpha$-tocopherol is exclusively secreted in chylomicrons. The small HDL particles selectively distributed $\alpha$-tocotrienol to organs and tissues high in adipose content i.e. epididymal fat, perirenal fat and skin. In contrast, $\alpha$-tocopherol was reported to be more evenly distributed based on the fact that LDL receptors are available in all tissues [24]. A clinical study reported that higher concentrations of tocotrienols were observed in adipose tissue surrounding benign than malignant breast 
cancer tumour [25]. The following study conducted by Fairus et al. [23] reported the similar trend of response using lower dose of treatments (526 TRF vs $537 \mathrm{mg} \alpha-$ tocopherol). The rapid disappearance of tocotrienols in the plasma within 24 hours triggered much debate on the bioavailability of tocotrienols on metabolic effects. This could be partly due to the low affinity of $\alpha$ tocopherol transport protein $(\alpha$-TTP) for tocotrienols. The repacking of $\alpha$-tocopherol in the liver into VLDL cholesterol suggests the longer shelf life and higher concentrations of $\alpha$-tocopherol in the plasma. However, it was postulated that $\alpha$-tocotrienol may be absorbed via an $\alpha$-TTP independent pathway [20]. In a biodistribution study involving surgical patients, total tocotrienols were detected at about $34 \mathrm{nmol} / \mathrm{g}$ in adipose tissues after 4 weeks supplementation of $400 \mathrm{mg}$ tocotrienols daily [26]. It is important to note that considerable amount of tocopherols and tocotrienols were also detected in the brain tissues, which were previously shown to have neuroprotective effects in animal studies. Despite studies showing inconsistent tocotrienol levels in human plasma, a recent report found that plasma vitamin E concentration can be part of a non-invasive measurements to facilitate the diagnosis of Alzheimer's disease [27]. Indeed, using a standardized and relatively sensitive method, plasma vitamin E levels can be explored as a blood biomarker for disease diagnosis or monitoring.

Several postprandial studies were also designed to investigate the pharmacokinetics of tocotrienols when administered orally. In Yap et al. [28], evident changes in the pharmacokinetic parameters were observed when TRF was supplemented under fed or fasted state [28]. Comparisons were made between 8 healthy male volunteers given $300 \mathrm{mg}$ mixed tocotrienols consisting approximately $87 \mathrm{mg} \alpha$-tocotrienol, $166 \mathrm{mg} \gamma$-tocotrienol and $43 \mathrm{mg} \delta$ tocotrienol under fasted state or after a high fat meal. The 24 hours area under curve $\left(\mathrm{AUC}_{0-\infty}\right)$ of tocotrienols were shown to be increased by at least 2 -fold in the fed state, corresponding with a decrease in the volume of distribution $(\mathrm{Vd})$. When tocotrienol homologues were analyzed individually, the maximum plasma concentrations (Cmax) for $\alpha-, \gamma^{-}$and $\delta$-tocotrienol reached 1.83, 2.13 and $0.34 \mu \mathrm{g} / \mathrm{mL}$ respectively. The significant increase in tocotrienol bioavailability under fed state was most probably due to the increase of TAG after a high fat meal, followed by bile secretion. In another study where tocotrienols were given at higher doses (296 mg $\alpha$-tocotrienol, $284 \mathrm{mg} \gamma$-tocotrienol and $83 \mathrm{mg} \delta$-tocotrienol), the peak plasma concentrations of $\gamma$-tocotrienol did not seem to increase proportionally, i.e. $2.79,1.55$ and $0.44 \mu \mathrm{g} / \mathrm{mL}$ for $\alpha$-, $\gamma$ - and $\delta$-tocotrienol [21]. Nevertheless, TRF used in these studies had a different composition in the context of the ratios of homologues. In a follow up study, similar trends were observed [23]. The peak plasma concentrations of tocotrienol homologues were comparable to the doses given, following the order of $\alpha>\gamma>\delta$. However, dose is not the only factor that affects the plasma concentrations of tocotrienols reflected in the blood circulation. Essentially, solubility of vitamin $\mathrm{E}$ in the intestinal lumen is the major determinant for absorption [29]. Emulsification by bile salt and lypolysis by pancreatic enzymes are essential intraluminal processes for lipid formulations [30,31]. In fact, Yap and Yuen [32] described a tocotrienol formulation in the form of colloidal dispersion for enhanced bioavailability. In this study, tocotrienols were formulated into self-emulsifying systems and their pharmacokinetics was studied in fasted healthy volunteers [32]. In the context of Cmax and $\mathrm{AUC}_{0-\infty}$, tocotrienols administered with self-emulsifying systems were increased by 2 to 4 -folds compared to non-emulsified tocotrienols. Although the half-lives of tocotrienols were reported to be approximately 4 to 5 -fold lower than that of tocopherols (4 hours vs 20 hours), a dosing schedule of twice daily is sufficient to reach the steady state within 3 days [28,33]. Results from the above studies facilitated our understanding on the pharmacokinetic parameters and biodistribution of tocotrienols, which are fundamental for the design of chronic clinical evaluations. In addition, these studies provided a guideline that acute doses of mixed tocotrienols ranging from $200 \mathrm{mg}$ to $1011 \mathrm{mg}$ were considerably safe for human consumption and no adverse events was reported.

\section{Clinical evidence and bioavailability}

In an effort to determine the therapeutic window for tocotrienols, a number of long term clinical studies were carried out using TRF and tocotrienol derivatives. The majority of these trials were focused on lipid profile as tocotrienols were found to inhibit HMG-CoA reductase [34-36]. However, the optimum dosing regimen to induce therapeutic effects remained unclear. Essentially, the treatment efficacy will depend on an array of variables including: 1) dose, 2) formulation, and 3) study populations. These factors will be discussed as follows.

\section{Dose}

In 1991, Tan and researchers found that TRF was able to decrease total, HDL, LDL cholesterol and TAG levels at a dose of $42 \mathrm{mg} /$ day [37]. Several dose escalation studies have been carried out over the next few years measuring lipid profile as the primary outcome. Wahlqvist et al. [38], Rasool et al. [39] and Rasool et al. [40] did not find significant changes in lipid profile after 2 to 4 months supplementation of $60 \mathrm{mg}$ to $320 \mathrm{mg}$ TRF daily [38-40]. Despite the lack of efficacy on lipid profile, Rasool and co-workers reported significant changes in aortic systolic blood pressure (ASBP) and augmentation index (AI) at 
dosage above $160 \mathrm{mg} /$ day [39]. When self-emulsifying TRF was used, supplementation at $50 \mathrm{mg}, 100 \mathrm{mg}$ and $200 \mathrm{mg}$ per day were able to lower the AI, while doses at $100 \mathrm{mg}$ and $200 \mathrm{mg} /$ day resulted in a significant reduction of carotid femoral pulse wave velocity (PWV) [40]. In fact, supplementation at $100 \mathrm{mg} /$ day demonstrated maximum decrease in AI with a reduction of $8.72 \%$ from baseline. Interestingly, Qureshi et al. [41] reported significant dose-dependent changes in lipid profile at doses of $25,50,100$, and $200 \mathrm{mg} /$ day [41]. Marked reduction in total, LDL cholesterols and apolipoprotein B-100 levels coupled with elevated HDL cholesterol and apolipoprotein A1 levels were observed with the lowest dose of $25 \mathrm{mg}$ TRF per day. Unfortunately, current evidence is insufficient to conclude the dose-dependent effect of TRF on lipid profile. While arterial compliance seemed to show consistent improvement with increasing TRF doses, more studies are needed to identify the cause of disparity among these studies.

\section{Formulation}

Although TRF is a common term used to describe a mixture of vitamin E rich in tocotrienols, several variations in composition and formulation of TRF are available in the market (Table 1). Using palm-based TRF (Palmvitee), Qureshi and co-researchers found that daily supplementation of $200 \mathrm{mg}$ TRF significantly reduced total, LDL cholesterols and apolipoprotein B-100 levels while HDL cholesterol, TAG and apolipoprotein A1 levels remained unchanged [42]. Platelet factor $4\left(\mathrm{PF}_{4}\right)$ and platelet aggregation were also suppressed after 28 days of supplementation. Contrary to Qureshi's findings, Mensink et al. [43] reported no significant changes on lipid profile and platelet aggregation in hypercholesterolemic subjects when supplemented with TRF preparation [43]. Similar observations were reported by Rasool et al. [40] using self-emulsifying TRF preparation (Tocovid Suprabio $^{\circ}$ ) [40]. However, when the dose was increased to $300 \mathrm{mg} /$ day, marked reductions in total and LDL cholesterol levels, as well as total/HDL cholesterol and LDL/HDL cholesterol ratios were observed without changing the HDL cholesterol and TAG levels [44].

On the other hand, tocotrienols extracted from rice bran oil were found to significantly reduce total, LDL cholesterols, apolipoprotein B-100 and lipoprotein(a) levels, consequently increasing the HDL/total cholesterol and HDL/LDL cholesterol ratios [41,52]. A more prominent decrease in total and LDL cholesterols was observed when the combination of $\mathrm{TRF}_{25}$ and lovastatin (HMGCoA reductase inhibitor) was used [53]. It should be highlighted that subjects participated in these studies were restricted to NCEP Step 1 or AHA Step 1 diet. The implementation of control diet as such may effectively alter the lipid profile, especially in hypercholesterolemic subjects with elevated total and LDL cholesterol levels. The AHA Step 1 guideline restricts daily intake of $<300 \mathrm{mg}$ cholesterol, $<10 \%$ energy from dietary saturated fats, and $\leq 30 \%$ energy from total fat $[56,57]$. Adherence to this diet might

Table 1 Summary of available tocotrienol formulations including source, delivery systems, excipients and composition of tocorienol homologues

\begin{tabular}{|c|c|c|c|c|c|c|}
\hline $\begin{array}{l}\text { Tocotrienol } \\
\text { formulations }\end{array}$ & Source & $\begin{array}{l}\text { Dosage } \\
\text { form }\end{array}$ & Delivery system & $\begin{array}{l}\text { Excipients and } \\
\text { vehicles }\end{array}$ & $\begin{array}{l}\text { Composition of tocotrienol } \\
\text { homologues }(\% \mathrm{w} / \mathrm{w})^{*}\end{array}$ & Reference \\
\hline Palm Vitee & Palm & Capsule & Oil suspension & Palm olein & a: $12-15 \%, y: 35-40 \%, \delta: 25-30 \%$ & {$[37,38,42,45-47]$} \\
\hline Tocovid Suprabio ${ }^{\circledR}$ & Palm & Capsule & $\begin{array}{l}\text { Self-emulsifying drug } \\
\text { delivery system }\end{array}$ & $\begin{array}{l}\text { Tween 80, Labrasol, Palm } \\
\text { olein/Soybean oil }\end{array}$ & a: $23.5 \%, \gamma: 43.2 \%, \delta: 9.8 \%$ & {$[22,26,28,40,44,48]$} \\
\hline Tocomin $^{\circledR} 50 \%$ & Palm & Emulsion & $\begin{array}{l}\text { Self-emulsifying drug } \\
\text { delivery system }\end{array}$ & $\begin{array}{l}\text { Tween 80, Labrasol, } \\
\text { Soybean Oil }\end{array}$ & a: $10.7 \%, \gamma: 21.6 \%, \delta: 6.4 \%$ & {$[32]$} \\
\hline $\operatorname{Tri}^{\oplus} \mathrm{E}$ & Palm & Capsule & Oil suspension & Palm superolein & $74 \%$ of mixed homologues ${ }^{* *}$ & {$[49-51]$} \\
\hline \multirow{7}{*}{$\begin{array}{l}\text { Tocotrienol-rich } \\
\text { fractions (TRF) }\end{array}$} & \multirow[t]{4}{*}{ Palm } & \multirow[t]{4}{*}{ Capsule } & \multirow[t]{4}{*}{ Oil suspension } & \multirow[t]{4}{*}{ Vegetable oils } & a: $34.6 \%, \gamma: 24.6 \%, \delta: 15.0 \%$ & {$[39]$} \\
\hline & & & & & a: $29.3 \%, \beta: 3.0 \%, \gamma: 28.1 \%, \delta: 8.2 \%$ & {$[21]$} \\
\hline & & & & & a: $29 . .8 \%, \beta: 2.9 \%, \gamma: 27.0 \%, 8: 8.6 \%$ & {$[23]$} \\
\hline & & & & & $66.7 \%$ of mixed homologues** & {$[43]$} \\
\hline & \multirow{3}{*}{$\begin{array}{l}\text { Rice } \\
\text { Bran }\end{array}$} & \multirow[t]{3}{*}{ Capsule } & \multirow[t]{3}{*}{ Oil suspension } & \multirow[t]{3}{*}{ Vegetable oils } & a: $14.6 \%, \beta: 2.2 \%, \gamma: 38.8 \%, \delta: 29.9 \%$ & {$[36]$} \\
\hline & & & & & $\begin{array}{l}\text { TRF25 containing a: } 15.5 \%, \beta: 1.6 \%, y: 39.4 \% \text {, } \\
\text { 8: } 5.2 \% \text {, desmethyl and didesmethyl: } 20.9 \%\end{array}$ & {$[41,52,53]$} \\
\hline & & & & & $\begin{array}{l}\text { Various compositionally different } \\
\text { tocotrienols supplements }\end{array}$ & {$[54]$} \\
\hline \multirow{2}{*}{$\begin{array}{l}\text { Individual } \\
\text { tocotrienol } \\
\text { homologues }\end{array}$} & \multirow[t]{2}{*}{ Palm } & \multirow[t]{2}{*}{ Capsule } & \multirow[t]{2}{*}{ Oil suspension } & Olive oil & $30 \mathrm{mg}$ of $\gamma \delta$-tocotrienols ${ }^{* *}$ & {$[55]$} \\
\hline & & & & $\begin{array}{l}\text { Medium-chain } \\
\text { triglyceride }\end{array}$ & $a, y$ and $\delta$-tocotrienyl acetate & {$[56]$} \\
\hline
\end{tabular}

*\% w/w of tocotrienol homologues calculated based on $\mathrm{g} / 100 \mathrm{~g}$ of total vitamin $\mathrm{E}$ content.

**Composition of individual tocotrienol homologue not specified. 
have an additive or synergistic interaction with TRF on lipid profile, bringing the total and LDL cholesterol levels to an acceptable range [58]. Nevertheless, having 4 homologues within the tocotrienols family, individual homologue might exhibit different potency in their biological effects. Using tocotrienols in the form of acetates, administration of $\alpha$ - and $\gamma$-tocotrienyl acetates for 8 weeks $(250 \mathrm{mg} /$ day $)$ along with a AHA Step 1 diet did not drastically change the lipid profile although total and LDL cholesterol levels were increased by $\delta$-tocotrienyl acetate [56]. However, a lower rate of the oxidation of LDL cholesterol was observed with the supplementation of $\alpha$ - and $\delta$-tocotrienyl acetates. Similarly, no changes in lipid profile were reported after 8-week supplementation of purified $\gamma$ - and $\delta$-tocotrienol mixture $(120 \mathrm{mg} /$ day $)$ despite the significant reduction in TAG level [55].

As summarized in Table 2, mixed results were observed for changes in lipid markers after long term supplementation of tocotrienols. The inconsistency might be attributed to the different compositions of TRF used. For example, $\mathrm{TRF}_{25}$ was extracted from rice bran oil having $17 \%$ to $21 \%$ of d-desmethyl and d-didesmethyltocotrienols which are not present in palm-based TRF $[41,52,53]$. In addition, the content of $\alpha$-tocopherol and ratios of the different homologues also vary among the TRF preparations. These variations need to be thoroughly understood before comparative conclusions can be made.

\section{Study population}

A number of clinical trials were conducted to examine the multi-faceted health benefits of tocotrienols in different populations. The bioavailability and efficacy of TRF may vary in different populations. Chin and coworkers [49] compared the absorption of tocotrienols in subjects with different age groups using $\mathrm{Tri}^{\circ} \mathrm{E}$ capsules [49]. After 6 months of TRF supplementation, it was observed that plasma tocotrienol levels increased significantly in participants aged above 50 years but not in younger group aged between 35 and 49 years. In accordance with the higher plasma concentrations of tocotrienols, decreased antioxidant enzyme activities, protein carbonyl and advanced glycosylation end products were observed in the elder group. These findings were in agreement with a previous study that reported reduced DNA damage in elderly group aged over 50 years [50]. In contrast, Heng et al. [51] reported higher plasma concentrations of tocotrienols in younger individuals ( $32 \pm 2$ years old) compared to older participants (52 \pm 2 years old) after 6 months supplementation of TRF [51]. Nevertheless in the context of plasma proteome, changes were observed following 3 months of TRF supplementation, in which 6 proteins were up-regulated in the older group whereas only 3 proteins were up-regulated in the younger groups.
This finding may suggest higher sensitivity towards TRF supplementation in the older participants, of which lower plasma concentrations were required to induce significant changes in protein expression.

The role of tocotrienols in the modulation of immune system was first established in animal models in 1999 [59-61]. Following that, Radhakrishnan and her team embarked on a clinical trial in healthy subjects to measure changes in T-lymphocytes, B-lymphocytes, natural killer cells and production of cytokines [62]. Although no significant effect was observed after 2 months of TRF supplementation, a further study revealed significant improvement in immune response in subjects challenged with tetanus toxoid (TT) [48]. The participants were supplemented with $400 \mathrm{mg}$ of TRF (Tocovid Suprabio ${ }^{\circ}$ ) per day and received an intramuscular TT vaccination on day 28. Plasma tocotrienol concentrations were increased significantly in the TRF-treated group on day 28 and 56. After 1 month of vaccination, the TRF- supplemented group had a higher increase in anti-TT IgG levels, interferon (IFN)- $\gamma$ and reduced cytokine secretions compared to the placebo group. Furthermore, Jubri et al. [45] reported the effect of TRF supplementation on immune response in cigarette smokers using a daily dose of $200 \mathrm{mg}$ Palmvitee capsules [45]. After 12 weeks supplementation, plasma levels of both tocopherols and tocotrienols were increased although the concentrations of tocopherols were higher. Yet, the plasma levels of tocopherols and tocotrienols showed no difference between smokers and non-smokers. Despite significant improvement in B cells percentage in the non-smoker group, T-cell profile was unaffected by the supplementation of TRF. It was postulated that the amount of TRF supplemented was insufficient to modulate the immune system in cigarette smokers.

In addition, there were several studies investigated the therapeutic efficacy of TRF supplementation on chronic diseases. Tomeo et al. [46] investigated the effect of TRF on patients with hyperlipidemia and carotid stenosis [46]. By supplementing the subjects with $300 \mathrm{mg} /$ day of Palmvitee for 12 months, 7 out of 25 subjects with carotid stenosis had improved disease progression. In another study involving patients with Type 2 diabetes mellitus and hyperlipidaemia, the supplementation of $6 \mathrm{mg} \mathrm{TRF} / \mathrm{kg}$ body weight was found to decrease total lipids, total and LDL cholesterol levels by $25 \%, 32 \%$, and $45 \%$ respectively [36]. The data interpretation may be confounded by the large variations observed at baseline suggesting a better powered study population may be needed. A recent study was conducted in patients undergoing surgical procedures to investigate the biodistribution of tocotrienols [26]. Among the 14 patients awaiting liver transplantation, 50\% of patients who had taken TRF supplementation showed a reduction in the model for end-stage liver disease (MELD) 
Table 2 Summary of changes in lipid profile after chronic supplementation of tocotrienols

\begin{tabular}{|c|c|c|c|c|c|c|}
\hline No & Reference & Study design & Subject (F/M) & Dose (per day) & Duration & Finding \\
\hline \multirow[t]{2}{*}{1} & Qureshi et al. [42] & $\begin{array}{l}\text { Double-blind, } \\
\text { crossover }\end{array}$ & $\begin{array}{l}25 \text { hypercholesterolemic } \\
\text { subjects }(11 \mathrm{~F} / 14 \mathrm{M})\end{array}$ & $200 \mathrm{mg}$ TRF & $\begin{array}{l}4 \text { weeks per } \\
\text { intervention }\end{array}$ & $\begin{array}{l}\text { Total cholesterol, LDL cholesterol, } \\
\text { ApoB: } \downarrow\end{array}$ \\
\hline & & & & $\begin{array}{l}300 \mathrm{mg} \text { corn oil } \\
\text { (placebo) }\end{array}$ & & HDL cholesterol, TAG, ApoA1: $\leftrightarrow$ \\
\hline \multirow[t]{5}{*}{2} & Tan et al. [37] & Single arm & $\begin{array}{l}\text { Preliminary study: } \\
9 \text { healthy subjects } \\
\text { (2 F/7 M) }\end{array}$ & $42 \mathrm{mg}$ TRF & 30 days & Total cholesterol: $\downarrow(n=3), \leftrightarrow(n=6)$ \\
\hline & & Single arm & Follow-up study: 22 & $42 \mathrm{mg}$ TRF & 30 days & Total cholesterol: $\downarrow(n=4), \leftrightarrow(n=18)$ \\
\hline & & & $\begin{array}{l}\text { healthy subjects } \\
\text { (0 F/22 M) }\end{array}$ & & & LDL cholesterol: $\downarrow(n=5), \leftrightarrow(n=17)$ \\
\hline & & & & & & HDL cholesterol: $\downarrow(n=3), \leftrightarrow(n=19)$ \\
\hline & & & & & & TAG: $\downarrow(n=2), \leftrightarrow(n=20)$ \\
\hline
\end{tabular}

3 Wahlqvist et al. [38] Randomized, double-blind parallel

4 Tomeo et al. [46]

Randomized double-blind parallel

5 Qureshi et al. [52] Randomized, double-blind parallel

6 Mensink et al. [43] Randomized, double-blind parallel

7 O' Byrne et al. [56] Randomized, parallel

8 Qureshi et al. [53]

Randomized, double-blind crossover

9 Qureshi et al. [41] Randomized, parallel
35 hypercholesterolemic subjects (19 F/ 16 M)

TRF

9, 18, 27, 36 mg TRF in palm superolein (placebo)

50 subjects with carotid artery atherosclerosis (27 F/ $23 \mathrm{M})$

160, 200, 240 mg TRF $300 \mathrm{mg}$ palm superolein (placebo)

41 hypercholesterolemic $200 \mathrm{mg} \mathrm{TRF} 25$ subjects (22 F/ 19 M)

$300 \mathrm{mg}$ tocopherolstripped corn oil (placebo)

40 mildly hypercholesterolemic subjects (0 F/40 M)

$160 \mathrm{mg}$ TRF/d

80 mg a-tocopherol (placebo)

51 hypercholesterolemic subjects (29 F/22 M)

$250 \mathrm{mg} \mathrm{a}-, \gamma^{-}, \delta-$ tocotrienyl acetate

250 mg mediumchain triacylglycerols (placebo)

28 hypercholesterolemic $50 \mathrm{mg} \mathrm{TRF} 25$ subjects (gender not specified)

90 hypercholesterolemic $25,50,100,200 \mathrm{mg}$ subjects (15 F/75 M) TRF $_{25}$

$2000 \mathrm{mg}$ tocolsstripped rice bran oil (placebo)

10 Baliarsingh et al. [36] Randomized, double-blind crossover

11 Rasool et al. [39]

Randomized, double-blind, parallel

12 Rasool et al. [40]

\section{T2DM subjects with hyperlipidemia (9 F/10 M)}

36 healthy subjects (0 F/36 M)

36 healthy subjects (0 F/36 M)
$6 \mathrm{mg} \mathrm{TRF} / \mathrm{kg}$ body weight

100 mg TRF-free rice bran oil (placebo)

80, 160, 320 mg TRF Corn flour (placebo)

50, 100, 200 mg TRF Soybean oil (placebo)
Randomized, double-blind parallel
16 weeks

Total cholesterol, LDL cholesterol, HDL cholesterol, TAG: $\leftrightarrow$

18 months Total cholesterol, LDL cholesterol, HDL cholesterol, TAG: $\leftrightarrow$

4 weeks per Total cholesterol, LDL cholesterol, phase $\quad A p o B, L p(a): \downarrow$

HDL cholesterol, TAG, ApoA1: $\leftrightarrow$

6 weeks Total cholesterol, LDL cholesterol, HDL cholesterol, TAG, Lp(a): $\leftrightarrow$

8 weeks Total cholesterol, LDL cholesterol: $\uparrow$ HDL cholesterol, TAG, ApoB, LDL/HDL cholesterol ratio: $\leftrightarrow$

175 days Total cholesterol, LDL cholesterol, ApoB, (35 days per Total/HDL cholesterol ratio, LDL/HDL phase) cholesterol ratio: $\downarrow$

HDL cholesterol, TAG: $\leftrightarrow$

105 days Total cholesterol, LDL cholesterol, (35 days per ApoB: $\downarrow$

phase)

HDL cholesterol, ApoA1: $\uparrow$

TAG: $\leftrightarrow$

60 days per Total cholesterol, LDL cholesterol: $\downarrow$ treatment

HDL cholesterol, TAG, Total/HDL cholesterol ratio, LDL/HDL cholesterol ratio: $\leftrightarrow$

2 months Total cholesterol, LDL cholesterol: $\leftrightarrow$

2 months Total cholesterol, LDL cholesterol: $\leftrightarrow$ 
Table 2 Summary of changes in lipid profile after chronic supplementation of tocotrienols (Continued)

\begin{tabular}{|c|c|c|c|c|c|c|}
\hline \multirow[t]{2}{*}{13} & \multirow[t]{2}{*}{ Zaiden et al. [55] } & \multirow{2}{*}{$\begin{array}{l}\text { Randomized, } \\
\text { double-blind, } \\
\text { parallel }\end{array}$} & \multirow{2}{*}{$\begin{array}{l}19 \text { hypercholesterolemic } \\
\text { subjects }(6 \mathrm{~F} / 13 \mathrm{M})\end{array}$} & 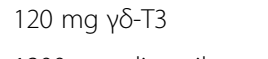 & \multirow[t]{2}{*}{8 weeks } & \multirow{2}{*}{$\begin{array}{l}\text { Total cholesterol, LDL cholesterol, HDL } \\
\text { cholesterol: } \leftrightarrow \\
\text { TAG: } \downarrow\end{array}$} \\
\hline & & & & $\begin{array}{l}1200 \mathrm{mg} \text { olive oil } \\
\text { (placebo) }\end{array}$ & & \\
\hline \multirow[t]{3}{*}{14} & \multirow[t]{3}{*}{ Yuen et al. [44] } & \multirow{3}{*}{$\begin{array}{l}\text { Randomized, } \\
\text { double-blind, } \\
\text { parallel }\end{array}$} & \multirow{3}{*}{$\begin{array}{l}32 \text { hypercholesterolemic } \\
\text { subjects }(12 \mathrm{~F} / 20 \mathrm{M})\end{array}$} & $300 \mathrm{mg}$ TRF & \multirow[t]{3}{*}{6 months } & \multirow{2}{*}{$\begin{array}{l}\text { Total cholesterol, LDL cholesterol, } \\
\text { Total/HDL cholesterol ratio, } \\
\text { LDL/HDL cholesterol ratio: } \downarrow\end{array}$} \\
\hline & & & & $\begin{array}{l}300 \text { mg soya bean oil } \\
\text { (placebo) }\end{array}$ & & \\
\hline & & & & & & HDL cholesterol, TAG: $\leftrightarrow$ \\
\hline
\end{tabular}

$\uparrow=$ significant increase; $\downarrow$ = significant decrease; $\leftrightarrow=$ no significant changes, $F=$ female, $M=$ male, T2DM = Type 2 Diabetes Mellitus.

score compared to $20 \%$ in tocopherol-supplemented patients. In cancer studies, the anti-cancer effect of tocotrienols was first discovered in the early 1990s when Nesaretnam et al. [63] reported the anti-proliferative effect of palm tocotrienols in breast cancer cells [63]. Following that, tocotrienols were found efficacious against prostate, pancreatic, colon, gastric and liver carcinomas in vitro and in vivo [64-68]. The first clinical trial of tocotrienols in cancer patients was embarked in 2006. This trial investigated the synergistic effect of TRF and tamoxifen in women with early breast cancer for 5 years [69]. The pilot clinical trial conducted in Hospital Kuala Lumpur, Malaysia, reported that the risk of dying from breast cancer seems to be reduced in patients taking TRF and tamoxifen compared to tamoxifen alone [3]. Although no significant advantage was observed with the supplementation of TRF in combination with tamoxifen for breast cancer specific survival, the risk of recurrence was $20 \%$ less in patients receiving combination treatment. When calculated using the numbers needed to treat, combination treatment may prevent one patient in every 30 from dying due to breast cancer [3]. This study suggested a possible synergistic effect of tocotrienols in combination with tamoxifen in the management of early breast cancer.

Summarizing the above studies, tocotrienols seemed to respond differently to a range of age groups but did not show consistent efficacies in the target study populations. Most of the studies conducted in patients with chronic diseases had relatively small sample size. This demonstrates the need to conduct randomized controlled trials in larger population to confidently evaluate the therapeutic potentials of tocotrienols.

\section{Limitations/recommendations}

Despite the lack of knowledge in the bioavailability of tocotrienols, several reviews in the past have ascertained the physiological functions of tocotrienols derived from both in vitro and animal studies collectively $[1,8,19,70]$. When these effects are not translated in clinical trials, inconsistency in the bioavailability of tocotrienols seems to be one of the major limitations. In fact, outcomes from clinical trials are dependent on various factors at many levels. One limiting factor is the dosage regimen, in which the reference dose for tocotrienols remains uncertain, and is most likely to differ for various indications. In such cases, dosage titration is fairly important in order to determine the optimum dose that demonstrates the highest efficacies and minimal possible side effects. More often than not, plasma tocotrienol concentrations serve as a reference to correlate absorption with therapeutic efficacies. Nevertheless, methods to quantify tocotrienols vary among research groups. A standard monograph for the quantification of tocotrienols is yet to be established, unlike tocopherol derivatives of which their monographs are regularly published in the British, European and United States Pharmacopoeias. Thus, a validated method with sufficient sensitivity for tocotrienols is critically needed. In fact, many analytical and validation studies for tocotrienols are underway, mostly focusing on oil matrix [71,72]. With the establishment of a quantification method, more mechanistic studies can be carried out, including the biodistribution and metabolism of tocotrienols. Debates on the transport pathways of tocotrienols and the role of $\alpha$-TTP remained inconclusive despite joint efforts from various research teams $[1,20]$. Imaging studies with tracking system attached to tocotrienols may provide insights into their distribution in tissues and vital organs. In addition, investigations via metabolomics may facilitate our understanding in the context of their metabolic pathways. This technique can provide information on possible interaction, alteration and realistic prediction on pharmacologic response of tocotrienols along their metabolic route. In this review, we identified three major factors affecting the bioavailability of tocotrienols, i.e. dose, formulation and study population. In addition, duration of study and background diet of participants contributed to the research outcomes in most cases. Long term tocotrienols supplementation with dietary intervention may provide accurate insights to the behavior of tocotrienols. Despite being the most convenient form of administration, oral consumption of tocotrienols might not provide the most suitable pharmacokinetic profile for certain indications. Other routes of administration should be explored, such as topical formulations for skin diseases and intravenous formulations for acute treatments. In cancer studies, intravenous formulations can provide a loading dose to achieve an immediate effect, 
followed by a sustained release formulation to maintain a long term effect. With the increasing knowledge on personalized medicine, formulating tocotrienols into different forms allows them to be used as a versatile therapeutic agent, with the added advantage of high tolerance being extracts from natural products.

\section{Conclusions}

In the context of bioavailability, there are convincing evidence that tocotrienols are detectable at appreciable levels in the plasma after short term and long term supplementations. There is insufficient data on the reference range of plasma concentrations of tocotrienols that are adequate to demonstrate significant physiological effects. Although the pharmacokinetics of tocotrienols are distinctly different from tocopherols which are well studied and remained longer in blood circulation, biodistribution study showed considerable accumulation of tocotrienols in vital organs. In the perspective of therapeutic efficacy, it is evident that the outcome of clinical evaluations is not only affected by the bioavailability of tocotrienols, but also closely dependent on the study designs. In view of the limited understanding, more comprehensive studies in the mechanisms of absorption are warranted.

\section{Competing interests}

The authors declare that they have no competing interests.

\section{Authors' contribution}

All authors contributed equally to the manuscript. All authors have read and approved the final manuscript.

\section{Acknowledgements}

The authors wish to thank the Malaysian Palm Oil Board for the support in writing this paper. Che H.L. and Tan D.M.Y are funded under the MPOB Graduate Students Assistantship Scheme for their postgraduate studies.

\section{Author details}

${ }^{1}$ Malaysian Palm Oil Board, 6 Persiaran Institusi, Bandar Baru Bangi, 43000 Kajang, Selangor, Malaysia. ${ }^{2}$ Department of Molecular Medicine, Faculty of Medicine, University of Malaya, 50603, Kuala Lumpur, Malaysia. ${ }^{3}$ International Medical University, No. 126, Jalan 19/ 155B, Bukit Jalil 57000, Kuala Lumpur, Malaysia. ${ }^{4}$ Nutrition Unit, Division of Product Development and Advisory Services, Malaysian Palm Oil Board, 6 Persiaran Institusi, Bandar Baru Bangi, 43000, Kajang, Selangor, Malaysia.

Received: 15 August 2013 Accepted: 8 January 2014

Published: 13 January 2014

\section{References}

1. Sen CK, Khanna S, Roy S: Tocotrienols in health and disease: the other half of the natural vitamin E family. Mol Aspects Med 2007, 28(5-6):692-728.

2. Nesaretnam K: Multitargeted therapy of cancer by tocotrienols. Cancer Lett 2008, 269(2):388-395.

3. Nesaretnam K, Meganathan P, Veerasenan SD, Selvaduray KR: Tocotrienols and breast cancer: the evidence to date. Genes Nutr 2012, 7(1):3-9.

4. Loganathan R, Selvaduray KR, Nesaretnam K, Radhakrishnan AK: Tocotrienols promote apoptosis in human breast cancer cells by inducing poly (ADP-ribose) polymerase cleavage and inhibiting nuclear factor kappa-B activity. Cell Prolif 2013, 46(2):203-213.

5. Selvaduray KR, Radhakrishnan AK, Kutty MK, Nesaretnam K: Palm tocotrienols decrease levels of pro-angiogenic markers in human umbilical vein endothelial cells (HUVEC) and murine mammary cancer cells. Genes Nutr 2012, 7(1):53-61.

6. Ray S, Kulkarni SS, Chakraborty K, Pessu R, Hauer-Jensen M, Kumar KS, Ghosh SP: Mobilization of progenitor cells into peripheral blood by gamma-tocotrienol: a promising radiation countermeasure. Int Immunopharmacol 2013, 15(3):557-564.

7. Khanna S, Roy S, Parinandi NL, Maurer M, Sen CK: Characterization of the potent neuroprotective properties of the natural vitamin $\mathrm{E}$ alpha-tocotrienol. J Neurochem 2006, 98(5):1474-1486.

8. Aggarwal BB, Sundaram C, Prasad S, Kannappan R: Tocotrienols, the vitamin $E$ of the 21st century: its potential against cancer and other chronic diseases. Biochem Pharmacol 2010, 80(11):1613-1631.

9. Choo YM, Ma AN, Chuah CH, Khor HT, Bong SC: A developmental study on the appearance of tocopherols and tocotrienols in developing palm mesocarp (Elaeis guineensis). Lipids 2004, 39(6):561-564.

10. Ng MH, Choo YM, Ma AN, Chuah CH, Hashim MA: Separation of vitamin E (tocopherol, tocotrienol, and tocomonoenol) in palm oil. Lipids 2004 39(10):1031-1035.

11. Schauss $A G$, Endres JR, Clewell A: Safety of unsaturated vitamin tocotrienols and their isomers. In Tocotrienols: Vitamin E beyond tocopherols. 2nd edition. Edited by Tan B, Watson RR, Preedy VR. Boca Raton, Florida: CRC Press, Taylor and Francis Group; 2013.

12. Nagendran B, Unnithan UR, Choo YM, Sundram K: Characteristics of red palm oil, a carotene- and vitamin E-rich refined oil for food uses. Food Nutr Bull 2000, 21(2):189-194.

13. Yap SP, Yuen $\mathrm{KH}$, Lim AB: Influence of route of administration on the absorption and disposition of alpha-, gamma- and delta-tocotrienols in rats. J Pharm Pharmacol 2003, 55(1):53-58.

14. Kulkarni S, Singh PK, Ghosh SP, Posarac A, Singh VK: Granulocyte colony-stimulating factor antibody abrogates radioprotective efficacy of gamma-tocotrienol, a promising radiation countermeasure. Cytokine 2013, 62(2):278-285.

15. Miyoshi N, Wakao Y, Tomono S, Tatemichi M, Yano T, Ohshima H: The enhancement of the oral bioavailability of gamma-tocotrienol in mice by gamma-cyclodextrin inclusion. J Nutr Biochem 2011, 22(12):1121-1126.

16. Fu JY, Blatchford DR, Tetley $L$, Dufes $C$ : Tumor regression after systemic administration of tocotrienol entrapped in tumor-targeted vesicles. J Control Release 2009, 140(2):95-99.

17. Fu JY, Zhang W, Blatchford DR, Tetley L, McConnell G, Dufes C: Novel tocotrienol-entrapping vesicles can eradicate solid tumors after intravenous administration. J Control Release 2011, 154(1):20-26.

18. Wong RS, Radhakrishnan AK: Tocotrienol research: past into present. Nut Rev 2012, 70(9):483-490.

19. Kannappan R, Gupta SC, Kim JH, Aggarwal BB: Tocotrienols fight cancer by targeting multiple cell signaling pathways. Genes Nutr 2012, 7(1):43-52.

20. Gee PT: Vitamin E - essential knowledge for supplementation. Lipid Technol 2011, 23(4):79-82.

21. Fairus S, Nor RM, Cheng HM, Sundram K: Postprandial metabolic fate of tocotrienol-rich vitamin E differs significantly from that of alpha-tocopherol. Am J Clin Nutr 2006, 84(4):835-842.

22. Khosla P, Patel V, Whinter JM, Khanna S, Rakhkovskaya M, Roy S, Sen CK: Postprandial levels of the natural vitamin $E$ tocotrienol in human circulation. Antioxid Redox Signal 2006, 8(5-6):1059-1068.

23. Fairus S, Nor RM, Cheng HM, Sundram K: Alpha-tocotrienol is the most abundant tocotrienol isomer circulated in plasma and lipoproteins after postprandial tocotrienol-rich vitamin E supplementation. Nutr J 2012, 11:5.

24. Gee PT: Unleashing the untold and misunderstood observations on vitamin E. Genes Nutr 2011, 6(1):5-16.

25. Nesaretnam K, Gomez PA, Selvaduray KR, Razak GA: Tocotrienol levels in adipose tissue of benign and malignant breast lumps in patients in Malaysia. Asia Pac J Clin Nutr 2007, 16(3):498-504.

26. Patel V, Rink C, Gordillo GM, Khanna S, Gnyawali U, Roy S, Shneker B, Ganesh K, Phillips G, More JL, et al: Oral tocotrienols are transported to human tissues and delay the progression of the model for end-stage liver disease score in patients. J Nutr 2012, 142(3):513-519.

27. Mangialasche F, Westman E, Kivipelto M, Muehlboeck JS, Cecchetti R, Baglioni M, Tarducci R, Gobbi G, Floridi P, Soininen H, et al: Classification and prediction of clinical diagnosis of Alzheimer's disease based on MRI and plasma measures of alpha-/gamma-tocotrienols and gamma-tocopherol. J Intern Med 2013, 273(6):602-621. 
28. Yap SP, Yuen KH, Wong JW: Pharmacokinetics and bioavailability of alpha-, gamma- and delta-tocotrienols under different food status. J Pharm Pharmacol 2001, 53(1):67-71.

29. Traber MG: Mechanisms for the prevention of vitamin E excess. J Lipid Res 2013:

30. MacGregor KJ, Embleton JK, Lacy JE, Perry EA, Solomon LJ, Seager H, Pouton CW: Influence of lipolysis on drug absorption from the gastro-intestinal tract. Adv Drug Deliv Rev 1997, 25(1):33-46.

31. Pouton CW: Lipid formulations for oral administration of drugs: non-emulsifying, self-emulsifying and 'self-microemulsifying' drug delivery systems. Eur J Pharm Sci 2000, 11(Suppl 2):S93-S98.

32. Yap SP, Yuen KH: Influence of lipolysis and droplet size on tocotrienol absorption from self-emulsifying formulations. Int J Pharm 2004 281(1-2):67-78

33. Julianto T, Yuen KH, Noor AM: Improved bioavailability of vitamin E with a self emulsifying formulation. Int J Pharm 2000, 200(1):53-57.

34. Khor HT, Ng TT: Effects of administration of alpha-tocopherol and tocotrienols on serum lipids and liver HMG CoA reductase activity. Int J Food Sci Nutr 2000, 51(Suppl):S3-S11.

35. Parker RA, Pearce BC, Clark RW, Gordon DA, Wright JJ: Tocotrienols regulate cholesterol production in mammalian cells by post-transcriptional suppression of 3-hydroxy-3-methylglutaryl-coenzyme A reductase. J Biol Chem 1993, 268(15):11230-11238.

36. Baliarsingh S, Beg ZH, Ahmad J: The therapeutic impacts of tocotrienols in type 2 diabetic patients with hyperlipidemia. Atherosclerosis 2005, 182(2):367-374.

37. Tan DT, Khor HT, Low WH, Ali A, Gapor A: Effect of a palm-oil-vitamin E concentrate on the serum and lipoprotein lipids in humans. Am J Clin Nutr 1991, 53(4 Suppl):1027S-1030S.

38. Wahlqvist ML, Krivokuca-Bogetic Z, Lo CS, Hage B, Smith R, Luldto W: Differential serum responses of tocopherols and tocotrienols during vitamin supplementation in hypercholesterolaemic individuals without change in coronary risk factors. Nutr Res 1992, 12:S181-S201.

39. Rasool AH, Yuen KH, Yusoff K, Wong AR, Rahman AR: Dose dependent elevation of plasma tocotrienol levels and its effect on arterial compliance, plasma total antioxidant status, and lipid profile in healthy humans supplemented with tocotrienol rich vitamin E. J Nutr Sci Vitaminol (Tokyo) 2006, 52(6):473-478.

40. Rasool AH, Rahman AR, Yuen KH, Wong AR: Arterial compliance and vitamin $\mathrm{E}$ blood levels with a self emulsifying preparation of tocotrienol rich vitamin E. Arch Pharm Res 2008, 31(9):1212-1217.

41. Qureshi AA, Sami SA, Salser WA, Khan FA: Dose-dependent suppression of serum cholesterol by tocotrienol-rich fraction (TRF25) of rice bran in hypercholesterolemic humans. Atherosclerosis 2002, 161(1):199-207.

42. Qureshi AA, Qureshi N, Wright JJ, Shen Z, Kramer G, Gapor A, Chong YH, DeWitt G, Ong A, Peterson DM, et al: Lowering of serum cholesterol in hypercholesterolemic humans by tocotrienols (palmvitee). Am J Clin Nutr 1991, 53(4 Suppl):1021S-1026S.

43. Mensink RP, van Houwelingen AC, Kromhout D, Hornstra G: A vitamin E concentrate rich in tocotrienols had no effect on serum lipids, lipoproteins, or platelet function in men with mildly elevated serum lipid concentrations. Am J Clin Nutr 1999, 69(2):213-219.

44. Yuen $\mathrm{KH}$, Wong JW, Lim AB, Ng BH, Choy WP: Effect of mixed-tocotrienols in hypercholesterolemic subjects. Funct Foods Health Dis 2012, 3:106-117.

45. Jubri Z, Latif AA, Top AG, Ngah WZ: Perturbation of cellular immune functions in cigarette smokers and protection by palm oil vitamin $\mathrm{E}$ supplementation. Nutr J 2013, 12:2.

46. Tomeo AC, Geller M, Watkins TR, Gapor A, Bierenbaum ML: Antioxidant effects of tocotrienols in patients with hyperlipidemia and carotid stenosis. Lipids 1995, 30(12):1179-1183.

47. Hayes KC, Pronczuk A, Liang JS: Differences in the plasma transport and tissue concentrations of tocopherols and tocotrienols: observations in humans and hamsters. Proc Soc Exper Biol Med Soc Exper Biol Med 1993, 202(3):353-359.

48. Mahalingam D, Radhakrishnan AK, Amom Z, Ibrahim N, Nesaretnam K: Effects of supplementation with tocotrienol-rich fraction on immune response to tetanus toxoid immunization in normal healthy volunteers. Eur J Clin Nutr 2011, 65(1):63-69.

49. Chin SF, Ibahim J, Makpol S, Abdul Hamid NA, Abdul Latiff A, Zakaria Z, Mazlan M, Mohd Yusof YA, Abdul Karim A, Wan Ngah WZ: Tocotrienol rich fraction supplementation improved lipid profile and oxidative status in healthy older adults: A randomized controlled study. Nutr Metab (Lond) 2011, 8(1):42.

50. Chin SF, Hamid NA, Latiff AA, Zakaria Z, Mazlan M, Yusof YA, Karim AA, Ibahim J, Hamid Z, Ngah WZ: Reduction of DNA damage in older healthy adults by Tri E Tocotrienol supplementation. Nutrition 2008, 24(1):1-10.

51. Heng EC, Karsani SA, Abdul Rahman M, Abdul Hamid NA, Hamid Z, Wan Ngah WZ: Supplementation with tocotrienol-rich fraction alters the plasma levels of Apolipoprotein A-I precursor, Apolipoprotein E precursor, and C-reactive protein precursor from young and old individuals. Eur J Nutr 2013, 52(7):1811-1820.

52. Qureshi AA, Bradlow BA, Salser WA, Brace LD: Novel tocotrienols of rice bran modulate cardiovascular disease risk parameters of hypercholesterolemic humans. Nutr Biochem 1997, 8:290-298.

53. Qureshi AA, Sami SA, Salser WA, Khan FA: Synergistic effect of tocotrienol-rich fraction (TRF(25)) of rice bran and lovastatin on lipid parameters in hypercholesterolemic humans. J Nutr Biochem 2001, 12(6):318-329.

54. Mustad VA, Smith CA, Ruey PP, Edens NK, DeMichele SJ: Supplementation with 3 compositionally different tocotrienol supplements does not improve cardiovascular disease risk factors in men and women with hypercholesterolemia. Am J Clin Nutr 2002, 76(6):1237-1243.

55. Zaiden N, Yap WN, Ong S, Xu CH, Teo VH, Chang CP, Zhang XW, Nesaretnam K, Shiba S, Yap YL: Gamma delta tocotrienols reduce hepatic triglyceride synthesis and VLDL secretion. J Atheroscler Thromb 2010, 17(10):1019-1032.

56. O'Byrne D, Grundy S, Packer L, Devaraj S, Baldenius K, Hoppe PP, Kraemer K, Jialal I, Traber MG: Studies of LDL oxidation following alpha-, gamma-, or delta-tocotrienyl acetate supplementation of hypercholesterolemic humans. Free Radic Biol Med 2000, 29(9):834-845.

57. Krauss RM, Eckel RH, Howard B, Appel $\sqcup$, Daniels SR, Deckelbaum RJ, Erdman JW Jr, Kris-Etherton P, Goldberg IJ, Kotchen TA, et al: AHA Dietary Guidelines: revision 2000: A statement for healthcare professionals from the Nutrition Committee of the American Heart Association. Stroke 2000 31(11):2751-2766.

58. Huang J, Frohlich J, Ignaszewski AP: The impact of dietary changes and dietary supplements on lipid profile. Can J Cardiol 2011, 27(4):488-505.

59. Gu JY, Wakizono Y, Sunada Y, Hung P, Nonaka M, Sugano M, Yamada K: Dietary effect of tocopherols and tocotrienols on the immune function of spleen and mesenteric lymph node lymphocytes in Brown Norway rats. Biosci Biotechnol Biochem 1999, 63(10):1697-1702.

60. Hafid SR, Radhakrishnan AK, Nesaretnam K: Tocotrienols are good adjuvants for developing cancer vaccines. BMC Cancer 2010, 10:5.

61. Ren Z, Pae M, Dao MC, Smith D, Meydani SN, Wu D: Dietary supplementation with tocotrienols enhances immune function in C57BL/6 mice. J Nutr 2010, 140(7):1335-1341.

62. Radhakrishnan AK, Lee AL, Wong PF, Kaur J, Aung H, Nesaretnam K: Daily supplementation of tocotrienol-rich fraction or alpha-tocopherol did not induce immunomodulatory changes in healthy human volunteers. $\mathrm{Br} J$ Nutr 2009, 101(6):810-815.

63. Nesaretnam K, Guthrie N, Chambers AF, Carroll KK: Effect of tocotrienols on the growth of a human breast cancer cell line in culture. Lipids 1995, 30(12):1139-1143.

64. Wada S, Satomi Y, Murakoshi M, Noguchi N, Yoshikawa T, Nishino H: Tumor suppressive effects of tocotrienol in vivo and in vitro. Cancer Lett 2005, 229(2):181-191.

65. Yap WN, Zaiden N, Luk SY, Lee DT, Ling MT, Wong YC, Yap YL: In vivo evidence of gamma-tocotrienol as a chemosensitizer in the treatment of hormone-refractory prostate cancer. Pharmacology 2010, 85(4):248-258.

66. Kunnumakkara AB, Sung B, Ravindran J, Diagaradjane P, Deorukhkar A, Dey S, Koca C, Yadav VR, Tong Z, Gelovani JG, et al: \{Gamma\}-tocotrienol inhibits pancreatic tumors and sensitizes them to gemcitabine treatment by modulating the inflammatory microenvironment. Cancer Res 2010, 70(21):8695-8705.

67. Manu KA, Shanmugam MK, Ramachandran L, Li F, Fong CW, Kumar AP, Tan P, Sethi G: First evidence that gamma-tocotrienol inhibits the growth of human gastric cancer and chemosensitizes it to capecitabine in a xenograft mouse model through the modulation of NF-kappaB pathway. Clin Cancer Res 2012, 18(8):2220-2229.

68. Zhang JS, Li DM, Ma Y, He N, Gu Q, Wang FS, Jiang SQ, Chen BQ, Liu JR: gamma-Tocotrienol induces paraptosis-like cell death in human colon carcinoma SW620 cells. PLoS One 2013, 8(2):e57779. 
69. Nesaretnam K, Selvaduray KR, Abdul Razak G, Veerasenan SD, Gomez PA: Effectiveness of tocotrienol-rich fraction combined with tamoxifen in the management of women with early breast cancer: a pilot clinical trial. Breast Cancer Res 2010, 12(5):R81.

70. Nesaretnam K, Meganathan P: Tocotrienols: inflammation and cancer. Ann N Y Acad Sci 2011, 1229:18-22.

71. Han NM, May CY: Chromatographic analyses of tocopherols and tocotrienols in palm oil. J Chromatogr Sci 2012, 50(3):283-286.

72. Yap SP, Julianto T, Wong JW, Yuen KH: Simple high-performance liquid chromatographic method for the determination of tocotrienols in human plasma. J Chromatogr B Biomed Sci App/ 1999, 735(2):279-283.

doi:10.1186/1743-7075-11-5

Cite this article as: Fu et al:: Bioavailability of tocotrienols: evidence in human studies. Nutrition \& Metabolism 2014 11:5.

\section{Submit your next manuscript to BioMed Central and take full advantage of:}

- Convenient online submission

- Thorough peer review

- No space constraints or color figure charges

- Immediate publication on acceptance

- Inclusion in PubMed, CAS, Scopus and Google Scholar

- Research which is freely available for redistribution 